\title{
OS BENEFÍCIOS DA CAPOEIRA NO TRATAMENTO DE USUÁRIOS DE UM CAPS: CENTRO DE ATENÇÃO PSICOSSOCIAL
}

\section{ARTIGO ORIGINAL}

MACHADO, Jônathan Oliveira ${ }^{1}$

SANTOS, Soraya Dayanna Guimarães ${ }^{2}$

MACHADO, Jônathan Oliveira. SANTOS, Soraya Dayanna Guimarães. Os benefícios da capoeira no tratamento de usuários de um CAPS: Centro de Atenção Psicossocial. Revista Científica Multidisciplinar Núcleo do Conhecimento. Ano 05, Ed. 05, Vol. 09, pp. 75-89. Maio de 2020. ISSN: 2448-0959, Link de acesso: https://www.nucleodoconhecimento.com.br/educacao-fisica/capoeira-notratamento

\section{RESUMO}

Utilizando como forma de embasamento os conceitos da reforma psiquiátrica, novos profissionais e recursos terapêuticos entraram em cena para compor o trabalho da saúde mental. O objetivo deste artigo é relatar os benefícios da utilização da oficina de capoeira como instrumento e recurso terapêutico no tratamento de pessoas com sofrimento psíquico, sendo os mesmos usuários do CAPS - serviço do Centro de Apoio Psicossocial, fazendo uso de uma entrevista semiestruturada com os usuários do CAPS. Esta pesquisa também apresenta, através de uma abordagem objetiva da saúde e qualidade de vida, expondo assim alguns dos métodos que a capoeira dispõe para ofertar como um meio psicoterapêutico, pois o tratamento nesse âmbito vai mais

1 Graduação em Educação Física licenciatura e bacharelado, pós graduado em Fisiologia do Exercício, pós graduado em Treinamento Personalizado.

2 Doutorado em Educação. Mestrado em Mestrado em Educação Brasileira. Especialização em Educação Física na Educação Básica. Graduação em educação física. 
além do que o uso de medicamentos psiquiátricos, sendo assim as oficinas e os medicamentos deve agir em conjunto nesse processo, chegando ao senso comum no que diz respeito aos benefícios que esse exercício pode proporcionar ao usuário do serviço.

Palavras-Chave: Capoeira, terapia, educação física, saúde.

\section{INTRODUÇÃO}

Nos fatores históricos a respeito da Saúde Mental, mostra de forma organizada, um aspecto da prática da área de Psiquiatria embasada em processos e meios de confinamento, maus tratos, exclusão de forma social e privação dos direitos de um cidadão, tratando desta maneira aos tidos como "loucos" mantidos numa espécie de cativeiro denominada de manicômios, que se encontravam distantes dos setores urbanos. Este formato de tratamento começou e ser revisto e contrariado a datar do rudimento do século passado, embasado pelo parecer crítico e protestos que encarretaram em uma grande manifestação da Reforma Psiquiátrica, dessa forma possibilitando transformar de forma efetiva a ingerência do Estado a respeito da geração de enfermidades mentais e sua forma de ser tratada.

Movimento este que teve início de seus trabalhos por meio dos anos 60, na Itália, lugar onde apareceram as convergências terapêuticas com as equipes multidisciplinares. Essa espécie de vivência, de forma principal, a proposta de tornar agentes principais as pessoas com de transtorno psíquico, foi cuidadosamente incorporada em âmbito global, crescendo definitivamente na desconfiguração da magnificência manicomial e crescimento dos direitos de cidadão das pessoas com esses tipos de transtornos mentais (NEVES, 2011).

Na sociedade brasileira, a apresentação da Reforma Psiquiátrica nos anos 70 ganhou um indispensável empurrão com tal Reforma, por meio da aprovação de meios jurídicos que deram início à mudança de uma sociedade que vivia exposta a situações decadentes de vida, sem nem um tipo de direito e sem dignidade, o que hoje é conhecido e denominado hospital psiquiátrico ou manicômio. Essa experiência 
mundial de anulação do antigo formato de saúde mental com foco no hospital psiquiátrico, que há muitos anos vem acontecendo em países de primeiro mundo, por fim encontrando sua versão brasileira nos Centros de Apoio Psicossociais (CAPS) distribuídos por todo o país. Tendo como principal objetivo criar métodos para promoção da saúde social, física e cognitiva, a partir da introdução de estilos de vida mais saudáveis no cotidiano, assim como de encontrar as melhores estratégias de reintegração desses usuários do serviço novamente à sociedade (PAIXÃO, 2009).

Os CAPS têm embasado suas atribuições dentro do molde conhecido das denominadas "oficinas terapêuticas", que se conceituam pela meta de fortalecer as ações dos usuários, na acepção de que possibilitem tomar outra direção de seus desejos, num movimento de produção corriqueira. Desta maneira, as oficinas são espontâneas, dinâmicas, lúdicas, centrada na pratica corporal, essa linha de raciocínio fica bem visível no relatório da III Conferência Nacional de Saúde (2002, p. 23-24), que aponta que, "As políticas de saúde mental devem ter como pressupostos básicos a inclusão social e a habilitação da sociedade para conviver com a diferença".

É dentro dessa perspectiva, que através de múltiplos aparates terapêuticos é oferecido a população brasileira à grandiosa e valiosa talhe na cultura brasileira, que a capoeira mostra acida em oficinas de vários CAPS em todo o território nacional. Desse modo expondo a capoeira não somente como uma atividade física ou cultural qualquer, e sim uma ferramenta terapêutica de importância considerável para o trabalho na área da saúde mental, auxiliando no tratamento dos pacientes da unidade, junto com o demais profissionais atuantes como educadores físicos, nutricionistas, farmacêuticos, psicólogos e psiquiatras, através de oficinas terapêuticas. A capoeira se apresenta no tratamento dos pacientes em clínicas de atenção psicossocial, sendo um meio de se trabalhar algumas qualidades nos pacientes que antes estavam escondidas atrás das dificuldades encontradas em suas complicações psíquicas (GOMES, 2015).

A arte ancestral da capoeira foi tombada de forma muito tardia em 2008 como patrimônio cultural imaterial brasileiro pelo Instituto Patrimônio Histórico e Artístico 
Nacional (IPHAN), com a contínua evolução e reconhecimento dessa arte, a capoeira em 2014 também foi tombada como patrimônio cultural imaterial da humanidade pela UNESCO - Organização Das Nações Unidas para a Educação, Ciência e Cultura. Essa modalidade não pode ser definida apenas por um aspecto, pois diz respeito a uma mistura entre luta, dança e jogo, sua origem é discutida até os dias de hoje, pois ainda não existe um estudo especifico que comprove a sua origem de fato, o que se tem são algumas especulações, a que mais se acredita é a de que a mesma nasceu no Brasil, criada por descendentes de africanos com envolvimento de características indígenas, pois a próprio termo capoeira se dá origem da palavra "caapoera" do dialeto indígena tupi-guarani, que significa mato ralo ou mato cortado, então o termo correto para se referir a capoeira, é como uma manifestação cultural afro indígena brasileira (MENDONÇA, 2014).

Atualmente a capoeira tem sido um instrumento de estudo nas mais diversas áreas do conhecimento, dessa forma podemos constatar esse fato na linha de raciocínio do autor Veronesi (2009, p.04) quando ele diz "Considera-se que as peculiaridades da Capoeira de Angola proporcionam melhores recursos para liberdade criativa de movimentos, buscam um jogo com maior diálogo corporal, menor competição e maior ludicidade", sendo assim, buscando compreender as suas mais variadas formas de apresentação, que vai desde a simples ação de diversão a tratamento terapêutico, sempre na procura de uma melhor qualidade de vida, bem estar e uma forma de inclusão social, sem distinção de cor de pele, poder aquisitivo, orientação religiosa ou sexual, tornando seus praticantes iguais perante o conhecimento cultural e princípios filosóficos do respeito pelo outro assim como ele é, proporcionado deste modo, uma vivência harmoniosa entre as pessoas, seja qual for sua origem (NASCIMENTO, 2019).

$\mathrm{Na}$ atualidade a capoeira está presente em estâncias diversas, como clubes, clínicas, academias e da mesma forma na área escolar, com dados embasados no Instituto Brasileiro de Geografia e Estatística (IBGE, 2017), somente no Brasil existem aproximadamente 10 milhões de adeptos da modalidade. A procura por exercícios físicos tem aumentado a cada ano, tendo em vista a importância da prática de 
atividades físicas relacionadas a qualidade de vida, pois segundo a Organização Mundial de Saúde (OMS) define a saúde como "um estado de completo bem-estar físico, mental e social, não somente como a ausência de doença, deste modo a capoeira tem em seu contexto metodológico a abrangência desses três fatores. A pretensão dos dados obtidos nesta pesquisa tem como principal foco: Verificar como a capoeira auxilia no tratamento terapêutico de pacientes de uma unidade do Centro de Atenção Psicossocial da cidade de Maceió - AL.

\section{MATERIAIS E MÉTODOS}

Este estudo consiste em uma pesquisa de campo com foco qualitativo, segundo Gaskel (2002) as pesquisas qualitativa permitem a compreensão minuciosa das motivações, atitudes, valores e crenças dos sujeitos pesquisados. Participaram desta amostra de forma voluntária, 5 (cinco) usuários de um CAPS do município de Maceió - AL, com vivências em aulas de capoeira dentro do serviço do mesmo. Para a elaboração dessa pesquisa foi utilizada uma entrevista semiestruturada (APÊNDICE) com 12 (doze) perguntas abertas. A entrevista em questão durou em aproximadamente 30 minutos, pois as perguntas eram muito pessoais, sendo assim os usuários tiveram tempos diferentes para expor suas respostas, alguns se mostraram mais objetivos, outros trabalharam mais suas explanações. Esta pesquisa foi autorizada pelo coordenador da unidade, que por sua vez concordou com o presente estudo, assinando e carimbando o Termo de Consentimento Livre e Esclarecido (TCLE).

Os participantes foram entrevistados durante o intervalo das oficinas de capoeira. Por sua vez foi utilizado para a análise dos dados coletados neste trabalho, um método de "análise de conteúdo". Para Bardin (2009), "a análise de conteúdo, enquanto método, torna-se um conjunto de técnicas de análise das comunicações que utiliza procedimentos sistemáticos e objetivos de descrição do conteúdo das mensagens", seguindo esta linha de raciocínio, a pesquisa em questão tem seu embasamento estruturado sob essa perspectiva, a seguir é possível observar os procedimentos realizados na entrevista exposto no quadro 1. 
Quadro 1. Fases da entrevista realizada e respectivos procedimentos

\begin{tabular}{|l|l|}
\hline FASES & PROCEDIMENTOS \\
É pedido ao sujeito que pense durante um minuto em \\
1. EVOCAÇÃO & $\begin{array}{l}\text { todas as coisas que julga benéficas e importantes a } \\
\text { respeito da participação do mesmo nas aulas de } \\
\text { capoeira no CAPS. }\end{array}$ \\
\hline 2ede-se ao entrevistado para responder um \\
questionário de forma sincera de acordo com os \\
fatores que o mesmo idealizou na fase anterior, e o \\
entrevistador anota as respostas em uma folha e grava \\
em um gravador. \\
3. AVERIGUAÇÃO
\end{tabular}

\section{RESULTADOS}

A verbalização dos sujeitos foram transcritas sob forma de classificadas em quatro categorias: A) Dificuldades nas aulas; B) Benefícios da capoeira; C) Evolução dos usuários durante as aulas de capoeira; e D) Capoeira hoje. As categorias são apresentadas no quadro 2 abaixo.

Quadro 2. Conteúdos Selecionados para as categorias estudadas.

\section{CATEGORIAS CONCEITO NORTEADOR}

A

DIFICULDADES

\section{NAS AULAS}

Os usuários entrevistados relatam suas maiores dificuldades quando iniciaram nas aulas de capoeira no caps. 
B

BENEFÍCIOS

\section{CAPOEIRA}

C

EVOLUÇÃO DOS USUÁRIOS DURANTE

AS AULAS DE

\section{CAPOEIRA}

\section{D}

\section{CAPOEIRA HOJE}

Os usuários entrevistados relatam quais os benefícios que a prática da capoeira proporcionou DA até o momento.

Os usuários descrevem se permanecem com as mesmas dificuldades que encontravam no início da prática de capoeira.

Com base nas categorias, uma síntese dos conteúdos obtidos foi realizada. O quadro

3 apresenta os conteúdos selecionados para cada categoria de análise.

Quadro 3. Ordem dos conteúdos para análise de suas respectivas categorias

\begin{tabular}{|l|l|}
\hline CATEGORIAS & $\begin{array}{l}\text { CONTEÚDOS } \\
\text { A }\end{array}$ \\
\begin{tabular}{|l} 
EIFICULDADES \\
falta de coordenação motora.
\end{tabular} \\
$\begin{array}{l}\text { Entrevistado 2. Eu senti a dificuldade de } \\
\text { movimentar os braços e as pernas ao mesmo } \\
\text { tempo. }\end{array}$ \\
$\begin{array}{l}\text { Entrevistado 3. O meu maior obstáculo no início, } \\
\text { foi me expressar, mas com ajuda dos colegas e do } \\
\text { professor, fez com que eu tivesse mais confiança } \\
\text { em mim mesmo. }\end{array}$ \\
\hline B & $\begin{array}{l}\text { Entrevistado 1. A capoeira me deixou mais } \\
\text { desinibida, pois antes eu sentia vergonha quando a }\end{array}$ \\
\hline
\end{tabular}




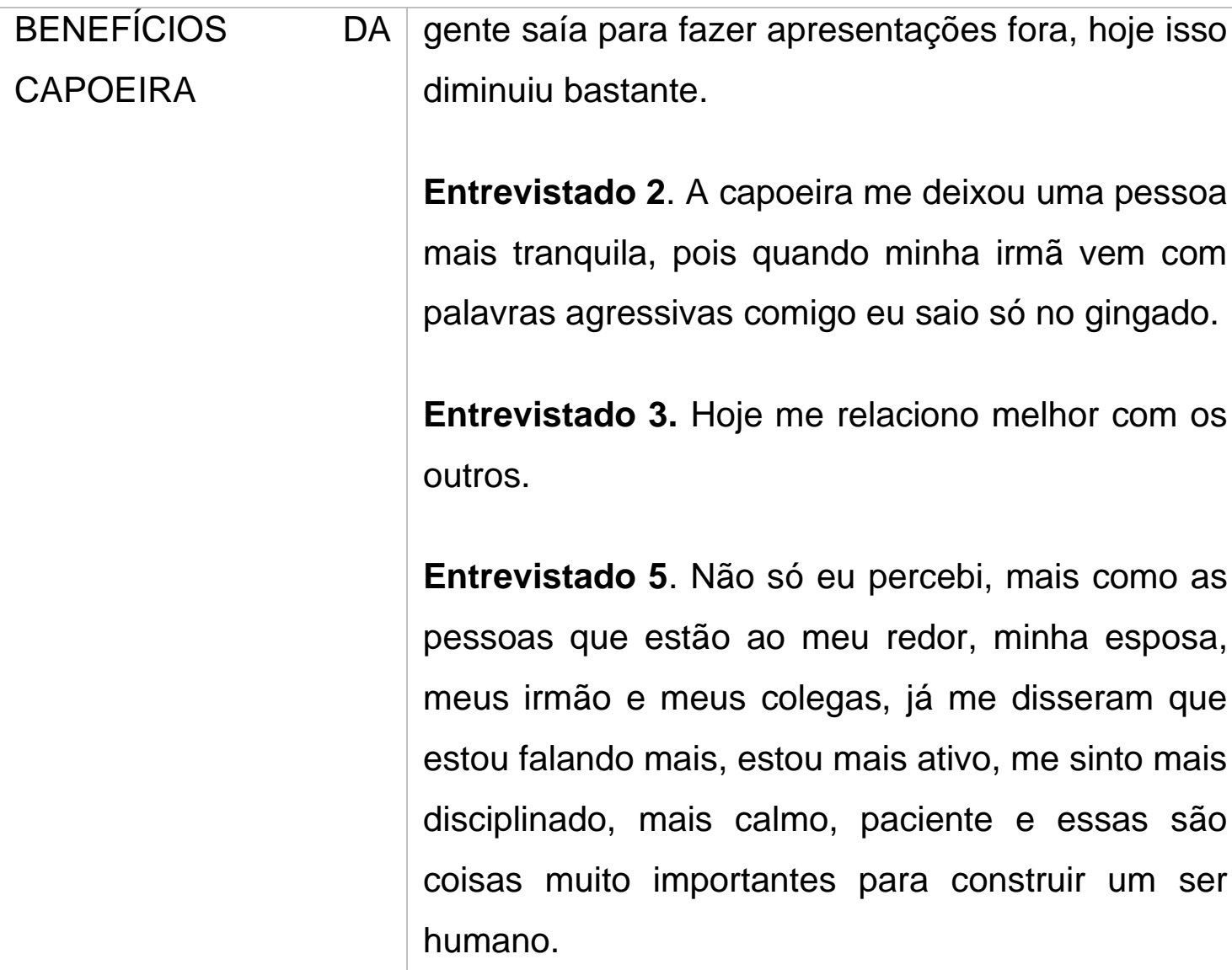

Entrevistado 2. Hoje me sinto mais solta, cheia de EVOLUÇÃO DOS energia.

USUÁRIOS DURANTE Entrevistado 5. Hoje eu me sinto mais livre, para AS AULAS DE me expressar, com mais confiança no que eu faço, CAPOEIRA sempre dentro do meu limite sem medo, porém o medo controlado é bom, pois ele deixa os outros sentidos em alerta, mais tudo tem que ter controle.

D

Entrevistado 1. A capoeira é muito boa na minha CAPOEIRA HOJE vida é minha diversão.

Entrevistado 2. Vejo a capoeira como minha alegria, eu gosto muito e hoje me sinto uma pessoa renovada. 
Entrevistado 5. Vejo como uma modalidade aberta, limpa que só tem a crescer.

\section{DISCUSSÃO}

\subsection{A - DIFICULDADES NAS AULAS}

Nesta categoria, perguntamos aos usuários quais foram as dificuldades no início das aulas de capoeira para cada um deles, pois qualquer indivíduo seja ele qual for, sempre apresentará dificuldades para uma prática antes desconhecida para o mesmo. Nesta linha de raciocínio devemos levar em consideração a fala do autor Hiene (2009), que por sua vez diz que, "deve-se pensar no desenvolvimento dos alunos, em que os domínios motor, físico, afetivo, cognitivo e social sejam contemplados". Dessa forma o entrevistado 1 relata que sua maior dificuldade foi: "Aprender a gingar, por causa da falta de coordenação motora", pois segundo Menuchi (2014, p. 02), "O professor tem um papel importante, pois pode influenciar decisivamente no contexto de ação, criando um ambiente de aprendizagem desafiador e rico em oportunidades de experimentações".

No desenvolver da entrevista o entrevistado 2 explanou a seguinte resposta: "Eu senti a dificuldade de movimentar os braços e as pernas ao mesmo tempo" sendo que o autor Pellegrini (2010, p.10) abordam que, "As habilidades perceptivo-motoras vão gradualmente sendo refinadas com a integração sensório-motora em constante harmonia", sendo assim a pratica da capoeira pode auxiliar no declínio dessas dificuldades expostas na entrevista semiestruturada. A capoeira não desenvolve somente os aspectos motores, pois na resposta do entrevistado 3 foi possível obter o seguinte resultado: "O meu maior obstáculo no início, foi me expressar, mais com ajuda dos colegas e do professor, fez com que eu tivesse mais confiança em mim mesmo", contribuindo com essa explanação o autor Freitas, (2007, p.01), fala que, "Por ser a capoeira uma arte repleta de ritmo, musicalidade, ela consegue ainda dar conta de todo o aspecto motor, cognitivo e afetivo do desenvolvimento humano", 
contudo pode ser trabalhado e desenvolvido dentro da pratica da capoeira os aspectos motores e sociais.

\subsection{B - BENEFÍCIOS DA CAPOEIRA}

Como forma de progredir o trabalho, nessa categoria foi questionado aos usuários, qual foi o benefício que a capoeira proporcionou para os mesmos, em relação aos benefícios que a pratica da capoeira oferece, o autor Leme (2009, p.07) relata que, "As vantagens para o corpo e a mente são diversas, e ela ajuda na socialização dentro da antropologia, sendo uma grande influência na beleza, equilíbrio, imagem, força e seus benefícios intelectuais". Nesta perspectiva o entrevistado $1 \mathrm{diz}$ em sua fala que, "a capoeira me deixou mais desinibida, pois antes eu sentia vergonha quando a gente saía para fazer apresentações fora, hoje isso diminuiu bastante", analisando a resposta do entrevistado 1, a capoeira possibilita o praticante a se tornar mais desinibido e combater a timidez, pois segundo o autor Pereira (2009, p.03) "aprendendo a tocar instrumentos como o berimbau, pandeiro e atabaque; a cantar em público, tornando-o mais desinibido e utilizando a música como forma de aprendizado", sendo assim a capoeira se mostra como uma ferramenta nesse processo.

O exercício da capoeira alivia o estresse e aumenta o autocontrole de quem a pratica, pois segundo o autor Leme, (2009, p.06), "a capoeira oferece inúmeros benefícios, entre eles é possível citar que, além de ser indicada para todas as pessoas, pois ajuda muito a combater o estresse, alterando beneficamente a qualidade de vida", pois na fala do entrevistado 2 expõe o seguinte relato, "a capoeira me deixou uma pessoa mais tranquila, pois quando minha irmã vem com palavras agressivas comigo eu saio só no gingado". A prática desse esporte estimula a socialização e o trabalho em equipe, pois segundo a linha de raciocínio do autor Silva (2011, p.01) "a capoeira possui características onde a sua inclusão no meio social é essencial", disto isto o entrevistado 3 complementa em sua fala quando diz que, "Hoje me relaciono melhor com os outros", nesse contexto fica claro a contribuição da pratica dessa atividade para a socialização, a inclusão e convivência em grupo de modo geral. 
Para a construção de ser humano é necessário o desenvolvimento de fatores contribuintes e essenciais, pois Segundo Soares (2011, p.01) "os conteúdos da capoeira ajudam na formação de seres humanos capazes de conviver com as diferenças" neste sentido podemos ver na pratica esse conceito exibido na fala do entrevistado 4, o mesmo deixa isso de forma explicita, vejamos seu relato, "Não só eu percebi, mais como as pessoas que estão ao meu redor, minha esposa, meus irmão e meus colegas, já me disseram que estou falando mais, estou mais ativo, me sinto mais disciplinado, mais calmo, mais paciente e essas são coisas muito importantes para construir um ser humano". A capoeira trabalha valores éticos e morais que ajudam na construção do cidadão, e não é diferente no dia a dia das aulas de capoeira no centro de apoio psicossocial.

\subsection{C - EVOLUÇÃO DOS USUÁRIOS DURANTE AS AULAS DE CAPOEIRA}

Nesta categoria foi explorada a questão de como o usuário evoluiu com a prática da capoeira em seu tratamento psíquico. Foi perguntado aos mesmos qual o benefício que as aulas trouxeram a eles, pois a capoeira fornece inúmeros benefícios para a saúde seja ela física, mental ou social, dessa forma melhorando a qualidade de vida do sujeito adepto dessa modalidade, pois segundo Hiene (2014, p.02):

Nesse aprendizado, desenvolve-se consciência corporal, além das principais capacidades físico-motoras como força, agilidade, flexibilidade, resistência e coordenação motora. Desenvolve-se também o autocontrole e o controle das emoções, sendo a calma um grande aliado do capoeirista.

Pois a capoeira proporcionou esses benefícios durante as aulas, podendo ser observado e constatado nas falas dos entrevistados 1 e 2, quando ambos dizem "Hoje me sinto mais solta, cheia de energia" e em seguida o entrevistado relatou, "Hoje eu me sinto mais livre, para me expressar, com mais confiança no que eu faço, sempre dentro do meu limite sem medo, porém o medo controlado é bom, pois ele deixa os 
outros sentidos em alerta, mais tudo tem que ter controle. Percebemos uma evolução dos usuários neste contexto, analisada e comprovada através deste estudo, pois a capoeira trouxe a eles benefícios que ajudaram a amenizar os seus sofrimentos psíquicos, proporcionando os mesmos uma melhor qualidade de vida, sendo assim segundo Veronesi (2009, p. 12), "defende-se a utilização da capoeira como método terapêutico por se tratar de uma iniciativa que desenvolve "tecnologia nacional" na área de atenção à saúde psíquica, bem como uma forma de prevenção", de modo geral trata-se a capoeira como um instrumento terapêutico e não somente como uma luta.

\subsection{D - CAPOEIRA HOJE}

No termino da entrevista, finalmente foi abordado e questionado, o que a capoeira hoje representa para cada um deles, essa questão foi de grande valia, pois a relação da pratica da capoeira com a vida do usuário faz toda a diferença para o seus respectivos tratamentos, visando a reinserção a sociedade e a recuperação dos mesmos. Sendo assim segundo o autor Veronesi (2009, p.10), "de certa forma, a Capoeira pode ser vista como uma estratégia de sobrevivência psicossomática desenvolvida contra um sistema que enxerga o ser humano como mercadoria".

Dessa forma a pratica da capoeira pode marcar a vida de seus adeptos de várias maneiras, tais como podemos ver a seguir na fala dos entrevistados 1, 2, 3, o primeiro fala de forma muito entusiasmada, "A capoeira é muito boa na minha vida é minha diversão", muitos desses usuários não tinham uma atividade lúdica em seu cotidiano, hoje com essa atividade agregada ao tratamento, eles sentem uma sensação de bem estar ao fazer parte da oficina, pois segundo Carneiro (2010, p.03), "O lúdico é inerente à atividade humana e se caracteriza por ser espontâneo, funcional e proporcionar satisfação", já o autor Pilates (2013, p.01) diz que, "a atividade não trabalha só as qualidades físicas. Ela exercita a atenção e ajuda a produzir endorfina, substância que aumenta o bem-estar, diminui o estresse e melhora a disposição" essa modalidade é capaz de proporcionar aos seus praticantes esses momentos de ludicidade. 
Em muitos casos, o que essas pessoas necessitam é um pouco de alegria, atenção e ser contagiadas com muita energia positiva, dessa forma essa linha de raciocínio é claramente complementada com a fala do entrevistado 2 que diz: "Vejo a capoeira como minha alegria, eu gosto muito e hoje me sinto uma pessoa renovada", sendo assim segundo Veronesi (2009, p.04) "tais distinções precisam ser ressaltadas porque dizem respeito à utilização da capoeira como instrumento terapêutico para usuários do CAPS". As atividades que envolvem muito mais que exercício físico como a capoeira, possibilita ao praticante o aumento de sua autoestima.

Existem práticas que são inclusivas de modo geral, como é o caso da capoeira que já é um símbolo de inclusão por si só, pois por se usar uma roda no momento do jogo, onde ninguém fica a frente de ninguém, tornado todos iguais. Podemos perceber isso na fala do entrevistado 3 "Vejo como uma modalidade aberta, limpa que só tem a crescer", pois a capoeira não escolhe classe social, cor, religião, desse modo não podendo ser contraindica por algum motivo. Segundo Matos (2008, p.01), a capoeira: "é praticada sem contra indicação por crianças, jovens, adolescente, adultos, terceira idade, pessoas portadoras de necessidades especiais", dessa forma se apresentando como uma ferramenta terapêutica de inclusão social.

\section{CONSIDERAÇÕES FINAIS}

A partir da análise de conteúdo realizada no presente estudo, podemos concluir que a capoeira como prática dentro dos CAPS, no cenário da saúde mental tem um compromisso de possibilitar aos usuários a estruturação, contribuição e benefícios no tratamento dos mesmos, esse processo ocorre de uma forma mais ampla possível. O método fundamental para o sucesso desta prática, sem duvida são suas características inclusivas, que podem possibilitar ao usuário adquirir autoconfiança, condicionamento, qualidade de vida e saúde mental, que os mesmos também podem vivenciar aspectos motores, cognitivos e afetivo-sociais da luta.

Dessa forma, a capoeira se apresenta como uma ferramenta eficaz nesse processo definitivamente, conforme a perspectiva deste estudo, com o foco de não somente 
formar um jogador de capoeira, e sim implantar a tematização dessa prática, visando contribuir na formação do cidadão, nesse contexto amenizando os sofrimentos psíquicos de seus praticantes, que possivelmente poderão usufruir da capoeira e de outras práticas da cultura corporal de movimento no cotidiano de seu tratamento, seguindo a vida da forma mais autônoma e saudável possível.

Por fim conclui-se de forma clara através desse aprofundado estudo, que é possível sim alcançar benefícios para os usuários de CAPS em seus respectivos tratamentos psiquiátricos através de oficinas terapêuticas como a capoeira, a mesma sendo ministrada por profissionais capacitados, com seus aspectos peculiares da prática, gerando um bem estar aos mesmos e uma melhor qualidade de vida, desta forma podendo trazer um pouco de esperança para essas pessoas com sofrimento psíquico.

\section{REFERÊNCIAS}

BARDIN, L. Análise de Conteúdo. Lisboa Portugal; Edições 70, LDA, 2009.

CARNEIRO, N. H, Aprendizagem da capoeira e desenvolvimento das capacidades físicas de pré-escolares por meio do lúdico, p. 03 jan/jun 2010.

FREITAS, J. L, Capoeira na educação física: como ensinar?" / Curitiba, Editora Progressiva, Revista Bueno Aires ANO 18 № 188, p. 01, 2007.

GASKEL, G. Metodologia da pesquisa, porto editora, Petrópolis, RJ, 2002.

GOMES, F. M. P, Capoterapia: "A capoeira angola como oficina terapêutica na reabilitação psicossocial de pessoas com diagnósticos de transtornos mentais", Ribeirão Preto - SP 2015.

HIENE, V. A Capoeira e seus benefícios, Centros de Praticas Esportivas da universidade de São Paulo, p. 01, São Paulo - SP 2014.

HIENE, V, Estilos de ensino e a iniciação da capoeira para crianças de 7 a 10 anos de idade, A revista Pensar a Prática, v. 12, no 1, p. 02, São Paulo - SP 2009. 
LEME, A. Um estudo dos Benefícios Físicos e Psicológicos da Capoeira, p. 07 Cuiabá - MT 2009.

MATOS, A, M. A capoeira na escola, Revista Virtú, Juiz de Fora, v.2, 2008.

MENDONÇA, A.S, Qualidade de vida dos idosos praticantes de capoeira na cidade de Maceió, Maceió - AL Brasil, TCC - Instituto brasileiro de ensino superior de Alagoas, 2014.

MENUCHI, M. R. T, A relação entre os alunos com dificuldades de coordenação motora e a participação nas aulas de educação física em uma escola de ilhéus BA, Revista Mackenzie de Educação Física e Esporte, São Paulo, v. 13, n. 2, p. 02, jul./dez 2014.

NASCIMENTO, D. Z, Saúde mental e as práticas multidisciplinares: Avanços, desafios, e novas perspectivas, revista Ciência e Saúde Coletiva, julho de 2019.

NEVES, A, S. CAPS-POEIRA: um modo de intervenção no CAPS-ad, Revista Malestar e Subjetividade - Fortaleza - Vol. XI - № 2, junho de 2011.

PAIXÃO, C. Análise da prevalência dos transtornos psíquicos na região metropolitana do Recife. In: Ciência \& Saúde Coletiva, Recife, v. 14, n. 1, p. 261-266, 2009.

PELLEGRINI, A. M, Desenvolvendo a coordenação motora no ensino fundamental, p. 10, Limeira - SP 2010.

PEREIRA, P. S. A Capoeira no Contexto Escolar, p. 03 Jequié - BA 2009.

PILATES, R, Revista Pilates, p. 01, 2013. Relatório Final da III Conferência Nacional de Saúde Mental. (2002). Brasília: Conselho Nacional de Saúde/ Ministério da Saúde.

SILVA, M. M, A capoeira como elemento de socialização e projetos sociais: o dito e o praticado, Revista Educação Meio Ambiente e Saúde, Espirito Santo, 2011. 
SOARES, E, A Inserção da Capoeira no Currículo Escolar, Revista Digital, p. 01, Bueno Aires, maio 2011.

VERONESI, F, A Capoeira como instrumento e recurso terapêutico para pessoas com sofrimento psíquico, p. 12, Santa Catarina, dezembro de 2009.

\section{APÊNDICE}

Roteiro De Entrevista

1. Nome

2. Idade

3. Quadro clínico

4. Há quanto tempo você frequenta o CAPS?

5. Há Quanto tempo você prática capoeira no CAPS? Quantas vezes por semana?

6. Como foi seu primeiro contato com as aulas de capoeira?

7. Você sentiu alguma diferença no seu dia a dia depois que começou a praticar capoeira

8. Como você se sente durante a aula de capoeira no CAPS?

9. A prática da capoeira lhe proporcionou algum benefício? Qual?

10. Qual a sua maior dificuldade quando você começou a praticar a capoeira?

11. Hoje você continua com essas dificuldades?

12. Como você vê hoje a capoeira na sua vida? Maior dificuldade, Beneficio, evolução, capoeira hoje.

Enviado: Março, 2020.

Aprovado: Maio, 2020. 